\title{
Publisher's Note to Modeling the influence of potassium content and heating rate on biomass pyrolysis [Appl. Energy J. 194 (2017) 199-211]
}

\author{
Anna Trubetskaya ${ }^{\mathrm{a}, *}$, Gerrit Surup $^{\mathrm{b}}$, Alexander Shapiro ${ }^{\mathrm{c}}$, Richard B. Bates ${ }^{\mathrm{d}}$ \\ ${ }^{a}$ Energy Engineering Department, Lulea University of Technology, 97187 Luleå, Sweden \\ ${ }^{\mathrm{b}}$ Department of Engineering Sciences, University of Agder, Jon Lilletuns vei 9, 4879 Grimstad, Norway \\ ' Department of Chemical and Biochemical Engineering, Technical University of Denmark, Søltofts Plads Bygning 229, Kgs. Lyngby 2800, Denmark \\ ${ }^{\mathrm{d}}$ MIT, Department of Mechanical Engineering, 02139 Cambridge, MA, USA
}

The authors and the editors regret to report that the following errors were found in the article after its availability online.

(1) In the online version, in Fig. 8, the font size of " $\mathrm{kg}_{I B}{ }^{-1}$ " should have had the same font size as the rest of the text.

(2) In the online version, under the nomenclature section, the descriptions should have been displayed in the same line with the words as follow:
$\mathrm{H}_{2} \mathrm{O} \quad$ water
max maximal
min minimal
pyr pyrolysis
total overall
mesh wire mesh
Re Reynolds number
$\Omega$ correction factor for influence of potassium content on activation energy $\left(\mathrm{E}_{\mathrm{a}, 3}\right)$

(3) In the print version, in the sentence: "In Fig. 6(b), the model estimates that char yield increases from $2.6 \%$ to $32.5 \%$ when the heating rates decrease from $10^{4}$ to $2 \mathrm{~K} \mathrm{~s}^{-1}$.", it should have been written " $\mathrm{K} \mathrm{s}^{-1}$ " instead of " $\mathrm{K} \mathrm{s}$ ".

(4) In the print version, the equation 19 has a typo in " $\mathbf{T}_{\mathbf{p} 3}$ ". The order " 3 " was written as subscript instead of superscript. The formula should be as follow:

$$
\lambda_{r}=\frac{4 \cdot \varepsilon}{(1-\varepsilon)} \cdot \varepsilon \cdot d_{p o r e} \cdot \sigma \cdot T_{p}^{3}
$$

(5) The word "demostrates" should be written as "demonstrates" in the sentence:

"Fig. 12 demonstrates that the rate of metaplast formation is slower than formation of volatiles and char at temperatures below $350^{\circ} \mathrm{C}$."

(6) The word "gase" should be replaced with "gas" in the sentence:

"Biomass firing is widely used for power generation. Danish pulverized fuel fired power plants are undergoing a transition to $100 \%$ biomass firing in order to reduce greenhouse gas emissions."

(7) Instead of $0.2,1$ and $5 \mathrm{~mm}$, we have to write in the sentence:

"Fig. 9 illustrates the mass loss of 0.2 and $1 \mathrm{~mm}$ pinewood particles."

The production staff of Applied Energy apologize for any inconvenience that may result from this oversight.

\footnotetext{
DOI of original article: http://dx.doi.org/10.1016/j.apenergy.2017.03.009

* Corresponding author.

E-mail address: anna.trubetskaya@ltu.se (A. Trubetskaya).
} 